\title{
Ein Maulaffe als Konkurrent
}

\section{Iris Ritzmann}

Prof. Dr. med. et lic. phil., Mitglied der Redaktion Medizingeschichte

Der Buchtitel allein schon ist Programm: «Deß getreuen Eckarths Medicinischer Maul-Affe oder der entlarvte Marckt-Schreyer», gedruckt in grossen roten und schwarzen Lettern. Der vielzeilige barocke Untertitel fasst zusammen, was die Leserschaft im Buch erwartet. Doch hierfür genügt eigentlich auch ein Blick auf das Frontispiz. Der «Maul-Affe» steht auf einer Bühne, gut erkennbar an seinem affenartigen Gesicht. Noch kurz zuvor trug er eine Maske und wollte seine Heilkünste anpreisen. Doch der "getreue Eckarth», dargestellt als adretter Herr rechts im Bild, hat ihm die Maske heruntergerissen, hält sie nun in seiner Rechten und zeigt sie dem amüsierten Publikum. Ehefrau und Diener des Heilers wenden sich nun erschrocken ab,
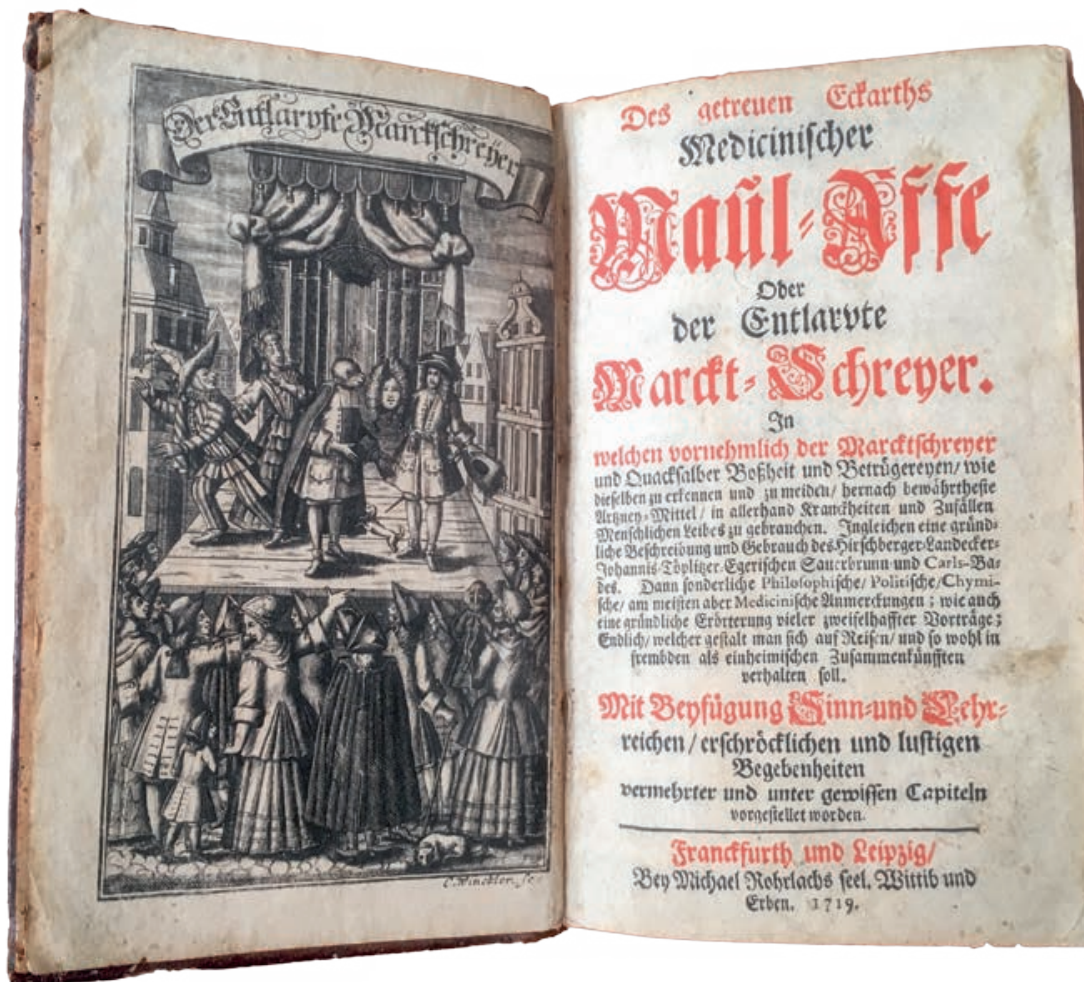

Johann Christian Ettner von Eiteritz: Deß getreuen Eckarths Medicinischer Maul-Affe oder der entlarvte Marckt-Schreyer, Frontispiz und Titelblatt, 2. Auflage 1719. Sammlung nicht einmal der Hund erkennt noch seinen Meister. Doch wer ist dieser "getreue Eckarth»? Hinter dem Namen verbirgt sich eine damals bekannte Sagenfigur, ein zuverlässiger und heldenhafter Freund und Berater, der sich in der deutschen Literatur von Tieck bis Goethe niedergeschlagen hat.

Der Autor, Johann Christian Ettner von Eiteritz (1654 bis 1724), war als praktischer Arzt in Breslau tätig. Nach vergeblichen Versuchen, eine Apotheke zu eröffnen, publizierte er sechs umfangreiche Romane, die sich gegen verschiedene Heilkundige wenden. Die Rede ist von einem "entlauffenen Chymicus», einem "ungewissenhafften Apotecker», einem "unwürdigen Doctor», einer "unvorsichtigen Hebamme» und schliesslich dem «medicinischen MaulAffen». Ihnen allen legt der «getreue Eckarth» das Handwerk.

Das hier vorgestellte Werk erschien 1719 und steht ganz im Zeichen des Konkurrenzkampfs, den studierte Ärzte gegen ihre nicht akademischen Kolleginnen und Kollegen letztlich erfolgreich führten. Es gelang ihnen, sich eine Vormachtstellung auf dem frühneuzeitlichen medizinischen Markt zu erkämpfen, notabene ohne dass sie bedeutend wirksamere Therapien, sicherere Eingriffe oder verlässlichere Heilmittel als ihre Konkurrenz einsetzen konnten.

\section{Bildnachweis}

Museum für medizinhistorische Bücher Muri (mmbm.ch) 